\title{
A Model of Methodology Need for AQAL Production System
}

\author{
Ziqiong Deng \\ Narvik Institute of Technology \\ Lodve Langes gt. $2 \bullet 8501$ Narvik $\bullet$ Norway \\ tel: (47) $76966215 \bullet$ fax: (47) 76966810 \\ e-mail: Ziqiong.Deng@hin.no
}

\begin{abstract}
s
This paper firstly makes a survey on computer integrated manufacturing, lean production, "keiretsu", and agile manufacturing. Then, definitions for production system (product-alliance oriented corporation), four-external-factors and four-internal-factors of production system, and AQAL (Attractive, Qualitative, Agile, and Lean) production system are given. Finally, a model of methodology need for AQAL production system is given as well.
\end{abstract}

\section{Keywords}

Enterprise integration, lean production, agile manufacturing, production system, methodology

\section{INTRODUCTION}

From the end of the seventies, the market have evolved. The level of competitiveness increased enormously. For meeting the challenge, enterprises have made great efforts to improve their system performances. Aiming at this, many new concepts and philosophies have been widely discussed and developed for aiding the improvement. The concepts and philosophies of computer integrated manufacturing, lean production, agile manufacturing, the "keiretsu", etc., are typical examples.

Facing the rich and varied new concepts and philosophies, it is necessary to make a survey of them to see what they will benefit the enterprises and what should be done further for the enterprises.

For this purpose, firstly, there is need to analyze the basic external market requirements to the enterprises; secondly, there is need to study the basic internal performance factors that the enterprises have to work with internally for meeting the external market requirements; then, it is necessary to derive a model to explain the need of methodologies which might be used by enterprises to aid them for improving their internal performances. In what follows in this paper, above questions are discussed in details. 


\section{FROM COMPUTER INTEGRATED MANUFACTURING TO AGILE MANUFACTURING}

From the end of the seventies, the level of market competitiveness increased with the appearance of new competitors coming from new geographical area. Then customers has become more and more exigent, searching cheapest products with appropriate quality, in shortest lead time.

At this time, on one hand, computer aided techniques for various functions in an enterprise such as Computer Aided Design (CAD), Computer Aided Planning (CAP), Computer Aided Manufacturing (CAM), Computer Aided Quality Control (CAQ), and Production Planning and Control (PP\&C) were installed in advanced enterprises forming many automation islands in one enterprise. On the other hand, the development of information technology such as local-area network communication and database technology in industries enables the possibility of enterprise-wide integration of those automation islands. Therefore, people started to further strengthen the research and implementation of enterprise integration Computer Integrated Manufacturing (CIM) for meeting the challenge of the increased level of competitiveness.

CIM involves in the internal integration within a single enterprise. A definition of CIM given by U. Rembold indicates that CIM combines the activities CAD, CAP, CAM, CAQ, and PP\&C in one system (Rembold, 1993).

Parallel to the CIM research and implementation, almost at the same period, some groups had been researching to find the reason of why the Japanese can produce products so good with so cheap price. Some of them found that the Japanese "weapon" is the Just-In-Time (JIT) approach. It provides for the cost-effective production and delivery of only the necessary quantity of parts at the right quality, the right time and the right place, while using a minimum amount of facilities, equipment, materials and human resources. It is dependent on the balance between the supplier's flexibility and the user's flexibility (Voss). Here, people notice the necessity of integrating the host enterprise as an user with the supply enterprises to obtain the just-in-time production.

In 1990, J. P. Womack, et al published their book, "The Machine that Changed the World", in which they first time define the Japanese production philosophy with a terminology "lean production" which is now well known around the world. They affirmed that the Japanese "weapon" is a new set of ideas and a new type of production system - lean production system, not just a dedicated new approach for material flow. A comparison was made by the authors of that book indicating that the lean production is lean because it uses less of everything compared with conventional mass production - half the human effort in the factory, half the manufacturing space, half the investment tools, half the engineering hours, and half the time to develop new products. It implies that the leanness is the central factor of a lean production system. The elements of lean production were figured as (1) running the factory, (2) designing the car, (3) coordinating the supply chain, (4) dealing with customers, and (5) managing the lean enterprise (Womack, 1990). This book revealed that the lean production system is a system not only involving the production in a host enterprise, but also the production in the supply chain, i. e., a cluster of supply enterprises, and the activities in the "dealing with customers" companies, i. e., a cluster of selling agencies.

Since 1989, a Japanese word "keiretsu" migrated to America, Europe, and even Asia. The most common meaning of "keiretsu" is something close to the English words "link," "connect," or "series." The general subject is related to Japan's industrial "families" (the various kinds of keiretsu). A horizontal keiretsu is a group of very large companies with common ties to a powerful bank. A vertical or pyramid keiretsu is made up of one very large company and hundreds or thousands of small companies subservient to it. A good example would be a large manufacturer like Toyota with twin vertical keiretsu within its total "group": one pyramid producing goods and the other pyramid distributing and selling those goods (Miyashita, 1996).

In 1991, R. N. Nagel, et al wrote a famous two-volume report entitled "21st Century Manufacturing Enterprise Strategy" in which they first time raise the concept of agile manufacturing and virtual corporation. They emphasize the agility as the central factor for an 
agile manufacturing system just as that Womack emphasizes the leanness as the central factor in a lean production system. Nagel indicated that Factory America Net is envisioned as a utility that will enable inter-enterprise integration and the virtual corporation. Inter-enterprise integration will tie a corporation into its entire supply base and its customers. It will tie together relevant pieces in each company in pursuit of a specific market opportunity (Nagel, 1991).

From lean production to "keiretsu" and to agile manufacturing, from the integration point of view, people today all emphasize that the success in world market is dependent not only on the successful integration within one single enterprise, but also on the successful integration of the cluster of enterprises.

As mentioned above, the agility is emphasized in the report "21st Century Manufacturing Enterprise Strategy" as the central factor of an agile manufacturing system, and agile manufacturing is affirmed to be the 21st century manufacturing (Nagel, 1991). As well, in the book "The Machine that Changed the World", the leanness is emphasized as the central factor for a lean production system, and the lean production is affirmed also to be "the standard global production system of the twenty-first century" (Womack, 1990).

What will be the 21 st century manufacturing? lean production, agile manufacturing, "keiretsu", or something else? From enterprises' standpoint, facing so many different new concepts and philosophies, how could enterprises absorb the advantages of those new concepts and philosophies to benefit their business? This is a matter which the author of this paper wants to discuss in the following sections.

\section{PRODUCTION SYSTEM - A CLUSTER OF ENTERPRISES}

As discussed above, we want to stand on the enterprises' standpoint to observe and absorb the advantages of new concepts and philosophies for benefiting the enterprises. From such a point of view, the market requirements are the main concern to the enterprises. None of enterprises would produce all components of a product, i.e., a product will be produced by a cluster of enterprises. Therefore, our discussion is focusing on a cluster of enterprises which are product-alliance oriented and we would call such a cluster of enterprises a production system.

Based on such an understanding to the production system, we would say that a production system is a chained enterprises based on a product alliance (or say a product corporation) which includes: (1) an input subsystem for inputs of raw materials and/or semifinished products (supply enterprises), (2) an output subsystem for outputs of finished products for marketing (selling agencies), and (3) a transform subsystem for transforming the inputs into the outputs (host enterprise) (see Figure 1).

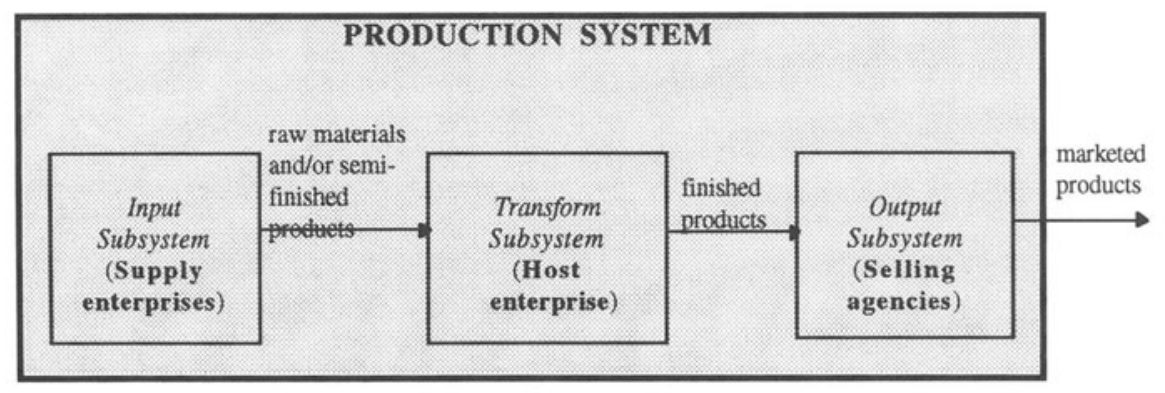

Figure 1 Concept of a production system

In Figure 1, the host enterprise plays a central role of producing products via transforming inputs into outputs. A cluster of supply-enterprises serves the host enterprise and playing a role for supplying host enterprise with raw materials and/or semi-finished products. 
A cluster of selling agencies serves also the host enterprise for selling products and feedbacking the market requirement information to the host enterprise.

For example, a host enterprise can be a car manufacturing company having its final product - car (See Figure 2). One of the "raw materials or semi-finished product" supplyenterprises of the car company may be a car radio company, and one other "raw materials or semi-finished product" supply-enterprise of the car company may be a steel metallurgy company, ..., etc.. Those enterprises are composed to be a production system (or a corporation) which is shown in the shaded part in Figure 2. With the same principle, we may also say that the car radio itself is a final product, the car radio company itself is a host enterprise and possesses its own "raw materials and/or semi-finished products" supplyenterprises such as the LSI (large-scale integrated) chip supply enterprise, ..., etc., forming one other production system (See top-left part of Figure 2). Again we may also say that the steel is a final product and the steel metallurgy company is a host enterprise possessing its own "raw materials and/or semi-finished products" supply enterprises forming another production system (See bottom-left part of Figure 2). Furthermore, the LSI chip manufacturing company can also be a host enterprise possessing its own "raw materials and/or semi-finished products" supply enterprises forming its production system, ..., and so forth.

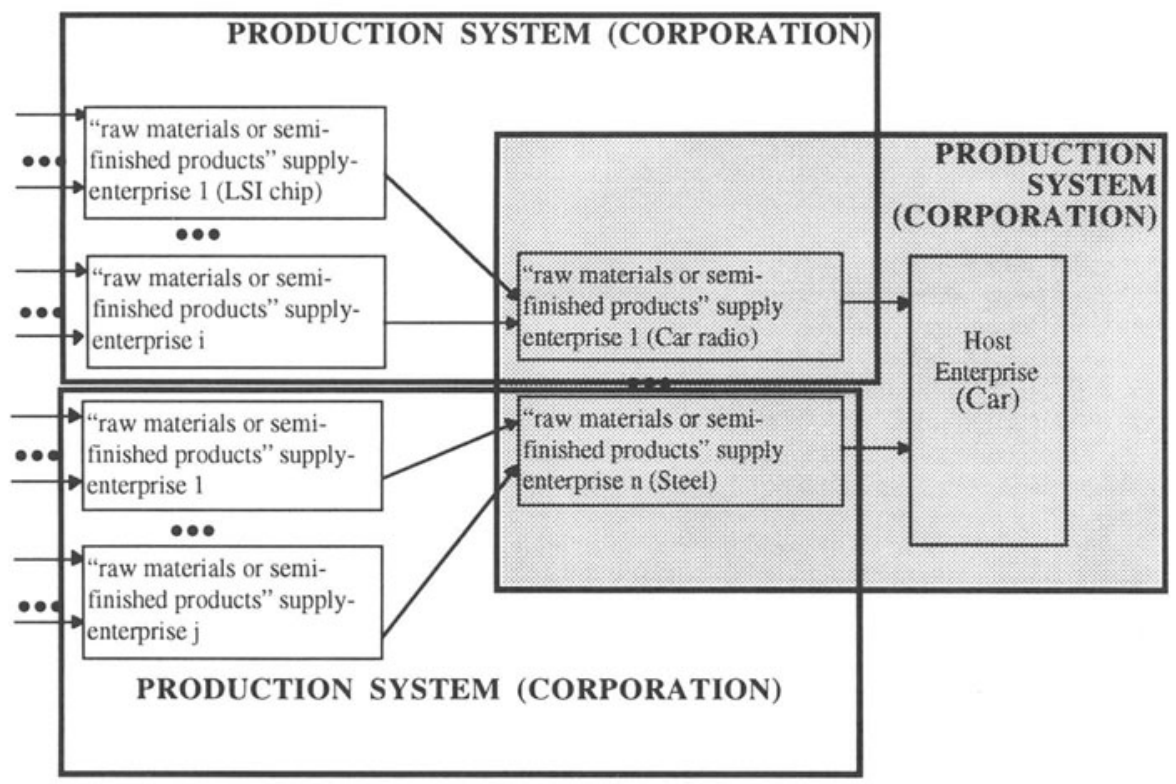

Figure 2 Hierarchy of corporations (production systems)

\section{ATTRACTIVE, QUALITATIVE, AGILE, AND LEAN PRODUCTION SYSTEM}

\subsection{External market factors of a production system}

The market concerns only products. Whoever can supply market with products which meet the customers' keenness and necessity with lowest price, satisfied quality, higher deliver speed of 
required quantity, who will take the competitive advantage. Therefore, we may say the external market factors which should be always considered by a production system are as follows:

- Keenness and necessity of customers (K),

- Quality required $(\mathrm{Q})$,

- Speed and quantity (S),

- Price (P).

The market keeps changing all the time, but the market factors are invariant. Say it in details, the keenness and necessity of products from customers $(\mathrm{K})$, the quality of products required from customers $(\mathrm{Q})$, the deliver speed of products and the quantity required from customers $(S)$, and the price $(P)$ keep changing all the time, however, at any time, the four market requirement factors, $\mathrm{K}, \mathrm{Q}, \mathrm{S}$, and $\mathrm{P}$, which a production system has to analyze are invariant.

Those four external market factors are fundamental and indispensable to a production system (see Figure 3). A production system has to behave best on all the four external market factors but not only one, two, or three of them.

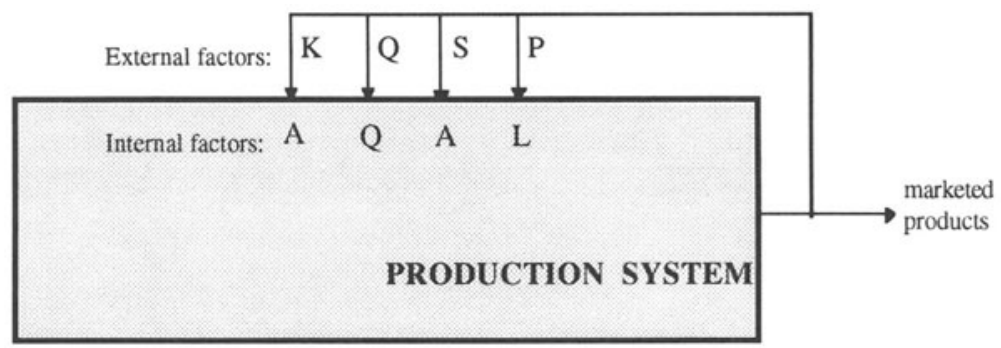

Figure 3 External and internal factors of a production system

\subsection{Four internal working factors of a production system}

As discussed above, a production system has to analyze and meet four external market factors. Obviously, inside a production system, all its internal functions and organizations should work together optimally and dynamically to improve its internal performances for meeting the changing external requirements.

What will be the common internal performances which the internal functions and organizations of a production system should work together to improve them for meeting the four external market requirements? It is easy to inference those performances as follows:

- Attractiveness of products (A),

- Quality of manufactured products $(\mathrm{Q})$,

- Agility of production (A),

- Leanness of production (L).

The first external requirement, keenness and necessity of customers, keeps changing, a production system internally should often work to innovate its products making them as attractive (A) as possible to the customers.

The second external requirement, quality required from customers, keeps changing, a production system internally should often work to improve its quality performances $(\mathbf{Q})$ such 
as quality design, quality manufacturing, quality control, and quality monitoring to meet quality requirement from customers.

The third external requirement, deliver speed of products and quantity of products required from customers, keeps changing, a production system has to improve its agility (A) to meet the changing external speed and quantity requirements.

The forth external factor, price, should be lowered again and again due to the market competitiveness, so a production system should internally try every best to decrease its production cost making its production as lean $(\mathrm{L})$ as possible.

Obviously, there exists a one-to-one relationship between the four external KQSP factors and the four internal AQAL factors as shown in Figure 3 and Table 1.

Table 1 Relationship between the four-external-factors and the four-internal-factors

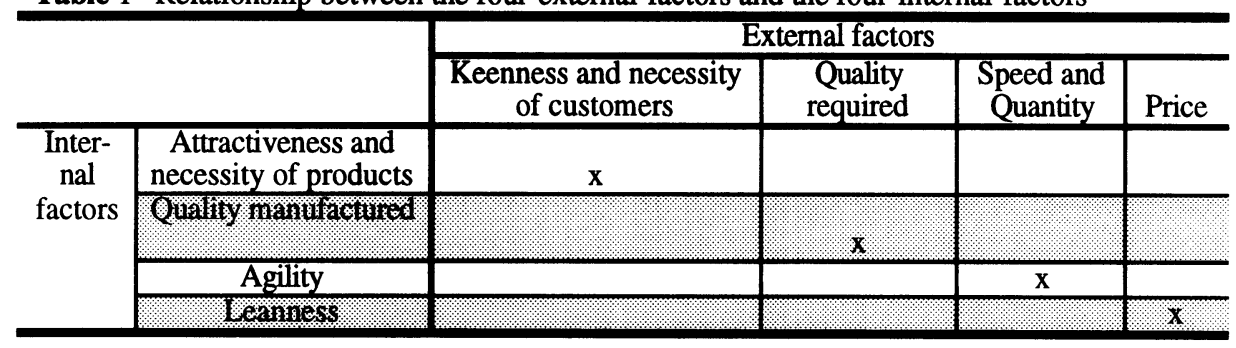

\subsection{AQAL production system}

To summarize above discussion, a production system has to meet all four external market requirements, but not only one, two, or three of them. Therefore, the production system has often to improve its all four internal performances, A (attractiveness), Q (quality of manufactured products), A (agility), and L (leanness), but not one, two, or three of them. In other words, the market requirements of KQSP factors are indispensable. Accordingly, the internal AQAL factors are also indispensable to a production system. Therefore, when we stand on the enterprises' standpoint, we say a production system could not only pursue to improve its agility, or leanness, or quality, or attractiveness, but all its AQAL performances. From this sense, we would like to say a production system should be an AQAL production system.

Of course, as an existing production system, sometime the product attractiveness is its main concern, so its internal functions and organizations would only concentrate their efforts to solve the product attractiveness problem. With the same principle, sometime the main concern of a production system may be the quality, or the agility, or the leanness, then their efforts may be concentrated on solving only one of those problems: the quality problem, the agility problem, or the leanness problem. However, when we try to plan and organize a new production system, then all AQAL factors should be taken into account. Therefore, in general looking, a production system should possess capabilities to solve all four indispensable AQAL problems.

\section{METHODOLOGY NEED FOR AQAL PRODUCTION SYSTEM}

We mentioned that the internal functions and organizations of a production system should cooperatively work together to improve their system to be AQAL. A further question is how they can make their system attractive, qualitative, agile, and lean. The answer is that they need methodology aid including tools. So in this section, we would first analyze the methodology need, then derive a model of methodology need to explain the scope of the need. 
For this purpose, we need first to analyze the relationship and cooperative manner of the internal functions and organizations as follows.

\subsection{Cooperative manner of Internal functions and organizations of AQAL production system}

We have mentioned that a production system consists of a host enterprise, a cluster of supplyenterprises, and a cluster of selling-agencies (See Figure 1). If we take a bit detail looking into the production system, we may say each enterprise or selling-agency internally has following three parts of functions and organizations (See Figure 4):

- Product-design (D) or Selling (Sel),

- Product-manufacturing (Mfg) or Service (Srv),

- Supervisory control and management $(\mathrm{Mgt})$.

From Figure 4, we see that, inside a host enterprise, three functions and organizations, Mgt, D, and Mfg, coordinate each other closely. Then functions in the host enterprise corporate also with the functions in the supply enterprises and selling agencies.

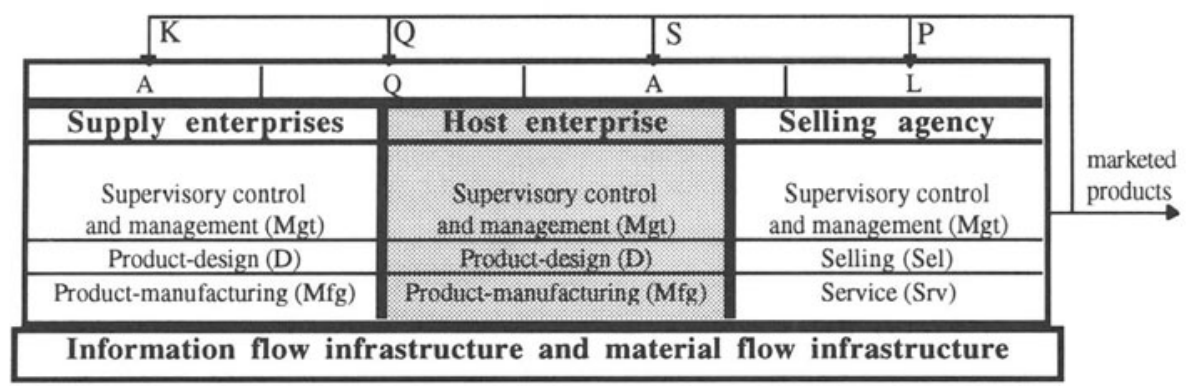

Figure 4 Relationship of internal functions of a AQAL production system

For example, if the system wants to improve their product attractiveness, then a work team may be organized. The team may be composed by persons from product-design organizations of host and supply enterprises, selling organization of selling agencies, manufacturing organization of host and supply enterprises, and management organizations of host and supply enterprises and selling agencies. The cooperative manners would be the team work manner with a concurrent engineering working principle. The working purpose is to improve the product attractiveness. With same principle, if the system wants to improve their leanness, or agility, or quality performance, or two, three, even all four of the AQAL performances, the work team can similarly be organized and working in team work manner with concurrent principle.

Incidentally, for enabling the team work and concurrent engineering, an efficient information flow infrastructure is needed making the team members distributed around a wide area being able to communicate each other of getting right information, at right time, to right location (See bottom of Figure 4). Also, for supporting agile, lean material (product) flow which starts from supply enterprises, to host enterprise, to selling agencies, and finally to customers, using for example JIT principle, an efficient material flow infrastructure is also needed to guarantee of getting right materials (products), at right time, with cheapest cost (See also bottom of Figure 4). In this paper, we will not further discuss the matters of 
infrastructures for brevity and will only discuss the methodology need for team work in a bit detail in what follows.

\subsection{A model of methodology need for AQAL production system}

From Figure 4, we mentioned that in a production system, no mater which function has the duty to work jointly for solving AQAL problems. So in Figure 5, we use one cube to represent host enterprise, another cube to represent supply enterprise. For brevity, we did not depict the selling agency cube in the Figure.

In Figure 5, we use three dimensions in a cube to represent three functions of an enterprise such as product-design function, product-manufacturing function, and supervisory control and management function. Each function has its duty to improve system performances of attractiveness, quality, agility, and leanness. Therefore, we mark every dimension with attractiveness, quality, agility, and leanness. In a sense, Figure 5 is a re-drawing of Figure 4. However, Figure 5 is better for expressing the methodology need than Figure 4.

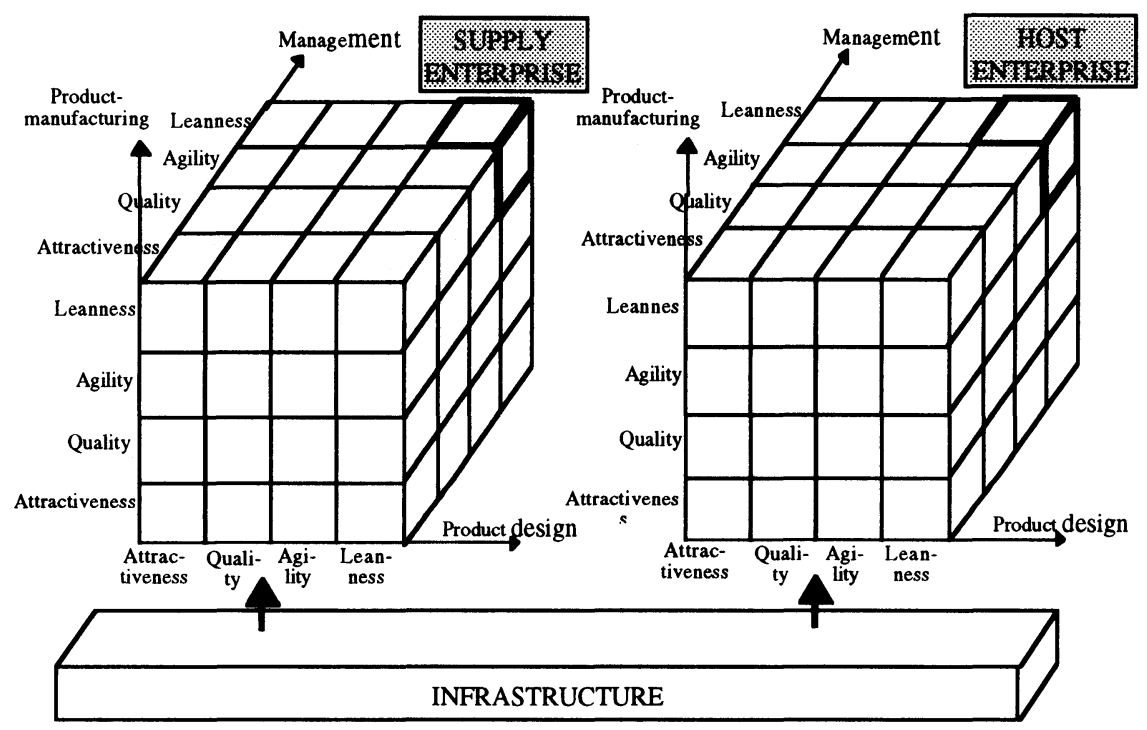

Figure 5 A model of methodology need for AQAL production

For example, if a production system wants to improve the leanness of the whole production system, then a work team should be organized which may be composed of partners coming from the management functions, product-design functions, and product-manufacturing functions in host enterprise, supply enterprises, and selling agencies (not shown in Figure 5). For the aids of fulfilling this task, a complete set of methodologies and tools are needed to help the team work for leanness improvement. What is the complete set of methodologies and tools for leanness improvement? they need to be further researched. We can first evaluate the existing available methodologies and tools. If they are powerful enough and fully match the working requirements, then we can fill them into the sub-cube which resides at the backupper-right corners of both the host enterprise cube and the supply enterprise cube of Figure 5 where their border are depicted with heavy bold lines. If those methodologies and tools are not complete for our purpose, additional developments should be taken.

The bold-lined sub-cubes in host and supply enterprises' cubes means that persons from design, manufacturing, and management organization of host and supply enterprises jointly 
work together on leanness improvement. The ingredients of the sub-cubes (which are now not filled in Figure 5) will indicate the complete set of methodologies and tools which can be used for leanness improvement.

The same idea applies to other sub-cube. For example, if a team is organized by persons from D, Mfg, and Mgt organizations of both host and supply enterprises, then the front-lowerleft corner' sub-cubes of host and supply enterprises are involved, in where we also need to fill in a complete set of methodologies and tools for aiding the attractiveness improvement. production.

Therefore, we use Figure 5 to define the scope of methodology need for the AQAL

\section{CONCLUSION}

In this paper, we mainly discusses what a production system and an AQAL production system are. Then, a model of methodology need is conceived which gives a scope of methodology need for AQAL production in where the need of how many complete sets of methodologies and tools is defined. However, there are a great bundle of further works needed for finding, editing, or developing the complete sets of methodologies and tools.

\section{REFERENCES}

Miyashita, K. and Russell, D. (1996) Keiretsu - Inside the Hidden Japanese Conglomerates, McGraw-Hill

Nagel, R. and Dove, R. (1992) Volume 1: 21st Century Manufacturing Enterprise Strategy An Industry-led View; Volume 2: 21st Century Manufacturing Enterprise Strategy Infrastructure, Iacocca Institute, Lehigh University

Rembold, U., Nnaji, B. O., and Storr, A. (1993) Computer Integrated Manufacturing and Engineering, Addison-Wesley

Voss, C. A., Just-In-Time Manufacture, Springer-Verlag

Womack, J. P., Jones, D. T., and Roos, D. (1990) The Machine that Changed the World, Harper Perennial 